\title{
SAFETY AND ENVIRONMENTAL ASPECTS OF HYLIFE-II
}

\author{
T. J. Dolan and G. R. Longhurst \\ Idaho National Engineering Laboratory \\ Post Office Box 1625 \\ Idaho Falls, ID 83415-2516 \\ 208-526-1649, 208-526-9950
}

\author{
EGG-M- - 90239 \\ DE91 006066
}

\begin{abstract}
The HYLIFE-II inertial confinement fusion reactor uses a Flibe spray for blast chamber protection and tritium breeding. HYLIFE-II is passively safe, having no large sources of energy available to disperse radioactive materials. The dominant activation product is $18 \mathrm{~F}$ (half-life 110 minutes). Only a small fraction $\left(<10^{-5}\right)$ of the Flibe activation products would be mobilized. The offsite dose from a severe accident involving simultaneous failure of the blast chamber and containment building would be $<0.2 \mathrm{mSv}$ (20 mrem), arid $N$-stamp requirements could be avoided in the blast chamber and coolant systems. The required tritium removal efficiencies are quantified.
\end{abstract}

\section{INTRODUCTION}

A preliminary study of HYLIFE.II safety and environmental issues has been described by Dolan and Longhurst. ${ }^{1}$ The dominant theme of HYLIFE-II is enhanced safety and minimal environmental impact. The use of Flibe instead of lithium removes the main safety hazard of HYLIFE-I (chemical energy of lithium-air or lithium-water reactions to mobilize radioactive materials). Five goals are proposed:

- Passive safety. The "early" offsite radiation dose (cloudshine during plume passage, 7 days of groundshine, plus the 50-year dose commitment from radioactivity inhaled during plume passage), without credit for active safety systems, should not exceed 2 Sv (200 rem), so there would be no early fatalities.

- Nuclear grade components. Minimize the volume of nuclear grade components to reduce cost and complexity.

- Routine effluents. Keep offsite dose from atmospheric releases < $50 \mu \mathrm{Sv} / \mathrm{yr}$ $(5 \mathrm{mrem} / \mathrm{yr})$, which requires tritium leakage less than $40 \mathrm{Ci} /$ day.
- Occupational risk. Maximize the portion of the reactor facility where dose rates are below $50 \mu \mathrm{Sv} / \mathrm{hr}(5 \mathrm{mrem} / \mathrm{hr})$. This reduces the need for remote maintenance.

- Waste management. Use materials and configurations that will permit either recycling of the Flibe and structure or Class C disposal (shallow land burial).

\section{ROUTINE RELEASE OF TRITIUM}

Tritium is removed by the blast chamber vacuum system, by a vacuum disengager in the primary coolant loop, and by an intermediate coolant detritiation system that may include a gas exchange column (Figure 1). A permeation barrier would not be effective in the intermediate heat exchanger (IHX) tubes, because tritium transport is limited by its diffusivity in the Flibe, not by diffusion through the tube wall.2 Because the fractions $f_{x}$ and $f_{\theta}$ of tritium leaking through the $\mathrm{IHX}$ and steam generator are substantial, we must achieve high separation fractions $i_{s}$ in the vacuum disengager and $f_{i}$ in the intermediate coolant detritiation system. Here we discuss the general features of vacuum disengager and the intermediate coolant detritiation system, which have not yet been designed, and deduce the required separation parameters.

Vacuum Disengager. The vacuum disengager will consist of a series of sprays of tiny Flibe droplets into vacuum chambers. As the droplets flow through the vacuum, part of the tritium diffuses out and is pumped away. By spraying the droplets upwards at an angle, their flight times can be prolonged. In order to avoid readsorption of tritium by other Flibe dropleis, the Flibe spray must not be optically thick.

At the blast chamber exit Flibe temperature of $923 \mathrm{~K}$, the tritium diffusion coefficient $D=6.4 \times 10^{-9} \mathrm{~m}^{2} / \mathrm{s}$. For a flight time $t=1 \mathrm{~s}$, the 


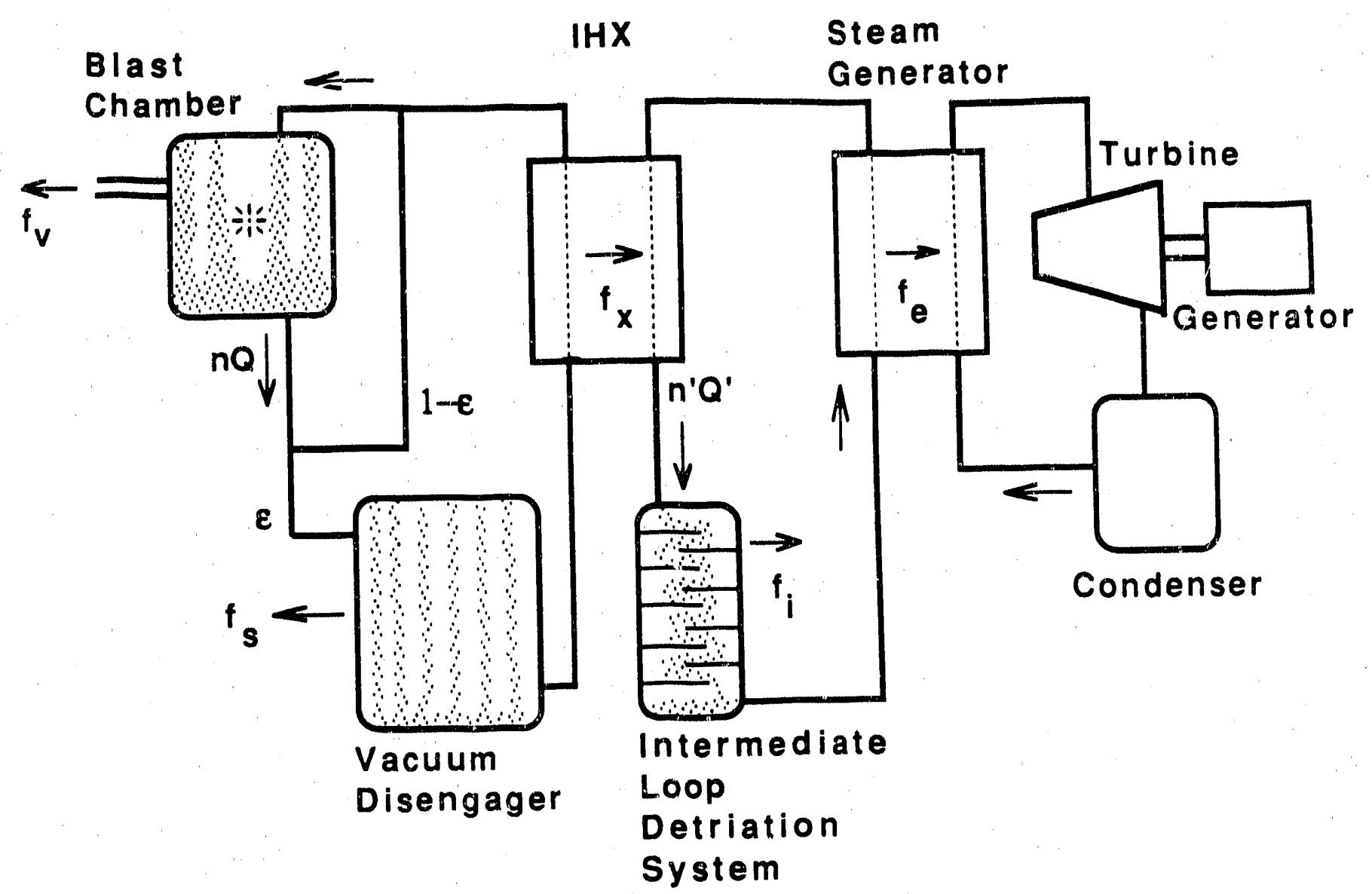

Figure 1. HYLIFE-II coolant system.

required droplet radius for significant diffusion to occur is

$$
a<(D t)^{1 / 2}=80 \mu \mathrm{m} .
$$

Augmentation of the effective value of $D$ by Hill's Vortex flow may permit larger droplets to be used. The vacuum disengager should remove about $99 \%$ of the tritium from the Flibe passing through it. Since the Flibe flow rate will be many $\mathrm{m}^{3} / \mathrm{s}$ and multiple stages in series may be needed, the disengager will be a large component.

\section{Intermediate Coolant Detritiation System.} $\mathrm{NaBF}_{4}$ has been chosen as the intermediate coolant, because of its favorable properties. ${ }^{3}$ Although this system has not been designed, hot $\mathrm{NaBF}_{4}$ may flow down an equilibration column, where it would contact pure $\mathrm{He}$ gas. Tritium leaving the $\mathrm{NaBF}_{4}$ would be carried by the He to a catalyst bed, where it would be oxidized. After cooling in a feedwater heater, the gas would be dried in a molecular sieve bed. Under favorable conditions, this method could

reduce the tritium concentration in the gas by factors $>10^{6} .4$ The gas exchange column should remove $>99 \%$ of the tritium from the $\mathrm{NaBF}_{4}$.

Tritium Flow Rates. To estimate the rate at which tritium escapes into the environment via the steam system, we define the following parameters: $\mathrm{C}=$ tritium consumption rate (atoms/s)

$F=$ rate of tritium injection in fuel pellets (atoms/s)

$f_{b}=$ pellet burnup fraction

$f_{\theta}=$ fraction of tritium atoms leaking irito the steam generator per pass of interinediate coolant

$f_{i}=$ fraction of tritium atoms removed by intermediate loop detritiation system

$f_{v}=$ fraction of unburned tritium fuel pellet atoms (F.C) removed by blast chamber vacuum system

$f_{s}=$ fraction of tritium atoms removed by vacuum disengager

$f_{x}=$ fraction of tritium atoms leaking into 
the intermediate loop per pass of the primary coolant through the $\mathrm{IHX}$

$n=$ tritium concentration in primary coolant leaving the blast chamber $\left(\mathrm{m}^{-3}\right)$

$n^{\prime}=$ tritium concentration in secondary coolant leaving the $\mathrm{IHX}\left(\mathrm{m}^{-3}\right)$

$P=$ reactor thermal power $(W)$

$Q=$ primary coolant volumetric flow rate $\left(\mathrm{m}^{3} / \mathrm{s}\right)$

$Q^{\prime}=$ intermediate coolant volumetric flow rate $\left(\mathrm{m}^{3} / \mathrm{s}\right)$

$R=$ tritium breeding ratio

$W=$ energy per fusion including energy multiplication in the structure $=3.20 \times 10^{-12} \mathrm{~J}(20 \mathrm{MeV})$

$\varepsilon=$ fraction of primary coolant passing through the vacuum disengager and $\mathrm{IHX}$.

The tritium consumption rate and injection rate are found from the equations:

$$
C=P /=f_{b} F \text {. }
$$

Calculations of tritium diffusion out of Flibe droplets show that only unburned fuel is effectively removed by the blast chamber vacuum system. From conservation of tritium atoms, we find their flow rate in the Flibe leaving the blast chamber to be

$$
n Q=\frac{F+(R-1) C-f_{v}(F-C)}{\varepsilon\left[1-\left(1-f_{s}\right)\left(1-f_{x}\right)\right]}
$$

Similarly, the tritium flow rate in the intermediate coolant leaving the $\mathrm{IHX}$ is

$$
n^{\prime} Q^{\prime}=\frac{\varepsilon f_{x}\left(1-f_{s}\right)}{f_{e}+f_{j}\left(1-f_{e}\right)} n Q \text {. }
$$

The tritium loss rate into the steam generator system is then

$$
L=f_{e}\left(1-f_{j}\right) n^{\prime} Q^{\prime} .
$$

From Eqs. (2) - (4) we note that $L$ is independent of the Flibe flow rate $Q$, of the intermediate coolant flow rate $Q^{\prime}$, and of the fraction $\varepsilon$ of Flibe passing through the IHX.
Example Case. For HYLIFE-II, $P=3 \mathrm{GW}$, $R=1.17$, and $\varepsilon=0.19$. We assume that $f_{b}=0.1$ and $f_{v}=0.95$. From detalled calculations of turbulent Flibe flow through the $\mathrm{IHX}$, we find that $\mathrm{f}_{\mathrm{x}}=0.065 .2$ Assuming that the tritium diffusivity in $\mathrm{NaBF}_{4}$ is 1.3 times its diffusivity in Flibe, we find $f_{\theta} \leq 0.69$. In order 10 achieve the goal $\mathrm{L}<40 \mathrm{Ci} /$ day, the required separation fractions are $i_{s}=0.99, f_{i}=0.99$. Then

$$
\begin{aligned}
\mathrm{nQ} & =8.1 \times 10^{21} \text { atoms } / \mathrm{s} \\
& =34 \mathrm{MCi} / \mathrm{day} .
\end{aligned}
$$

The tritium flow rate in the $\mathrm{NaBF}_{4}$ leaving the IHX is

$$
\begin{aligned}
n^{\prime} Q^{\prime} & =1.0 \times 10^{18} \text { atoms } / \mathrm{s} \\
& =4.2 \mathrm{kCi} / \mathrm{day},
\end{aligned}
$$

and the leakage into the steam generator is

$$
L=29 \mathrm{Ci} / \text { day. }
$$

If double containment is employed on ducts and other components, then tritium loss through the heat exchangers will be the dominant release pathway.

Tritium Inventories. For accident analyses it is useful to know the tritium inventories in the primary and intermediate coolant loops. The total volumetris flow rates of the Flibe and $\mathrm{NaBF}_{4}$ are $Q=66 \mathrm{~m}^{3} / \mathrm{s}$ and $Q^{\prime}=11.8 \mathrm{~m}^{3} / \mathrm{s}$, so the corresponding tritium concentrations leaving the biast chamber and $\mathrm{IHX}$ are

$$
\begin{aligned}
& n=1.23 \times 10^{20} \text { atoms } / \mathrm{m}^{3}, \\
& n^{\prime}=8.47 \times 10^{16} \text { atoms } / \mathrm{m}^{3} .
\end{aligned}
$$

At $T=923 \mathrm{~K}$, the Henry's Law solubility of tritium in Flibe is $S=8.25 \times 10^{14}$ molecules $/ \mathrm{m}^{3} \cdot \mathrm{Pa}$, and the corresponding tritium pressure

$$
p=0.5 n / S=75 \mathrm{kPa} \text {. }
$$

Although tritium solubility in $\mathrm{NaBF}_{4}$ is not quantified, it is reputed to be much higher than in Flibe, so tritium pressure in the intermediate loop will be low. (If $S \sim 1017$, then $p \sim 1 \mathrm{~Pa}$.) 
Tive aiticim inventories in the primary and intermediate coolants are on the order of $\mathrm{kCl}$ and $\mathrm{Cl}$, respecively, and are not of concern for accidental release. However tritum holdup in the blast chamber aid Flibe duct walls is much greater, on the order of $\mathrm{MCi}$. Much additional tritium $(\mathrm{kg}$ quanl: (es) will bo located in the target factory, pellet injection system, and their tritium systems (nol yet designed).

\section{SEVERE ACCIDENTS}

Orly a small fraction of the radioactive inventory of HY! IFE.Il could be mobilized, because there is little free energy available from chemical reactions or coolant pressure. Here we consider a severe accident producing simultaneous failures of the blast charnber and containment building. Containment failure must be postulated in order to produce significani orfsite consequences, but its probability would be very low.

Blast chamber fallure. If no Flibe curtain shielded the blast chamber wall, then all of the alpha energy $(70 \mathrm{MJ})$ plus a small fraction of the neutron energy would be deposited in the chamber wall. (Most of the neutron energy would pass through the wall.) The energy density deposited in the wall would be much lower than that required to cause catastrophic failure, so the most likely failure mode would be gradual crack propagation (enhanced by stress corrosion) from repeated blasts without adequate wall protection, followed by loss of vacuum, preventing further shots.

Afterheat. The decay heat in the SS-316 wall is given by the equation

$$
P=7 t^{-0.413} \quad \mathrm{MW}
$$

where $t$ is the time (s). If the chamber were perfectly insulated with an initial temperature of $300 \mathrm{~K}$, its temperature after 30 days would be $1280 \mathrm{~K}$, which is below the melting temperature $(1700 \mathrm{~K})$. About $2 \mathrm{MW}$ of afterheat would also be produced in the Flibe by $18 \mathrm{~F}$ (110 $\mathrm{min}$. half-life), but only about $4 \%$ of that would be the blast chamber. The Flibe adiabatic temperature rise after 30 days would be $170 \mathrm{~K}$. Thus, afterheat would not cause significant vaporization of the Flibe or structure. Afterheat could also facilitate oxidation, but Flibe and stainless steel are fairly stable and resistant to oxidation below $900 \mathrm{~K}$.
Filibe aerosol release. It has been estimated that $8.8 \mathrm{~kg}$ of Flibe vapor at $5000 \mathrm{~K}$ would be produced per shot in HYLIFE-11.5 About $6.10 \mathrm{~ms}$ after the blast a uniform vapor pressure would be established in the chamber, and massive transient condensation would begin. The average vapor density would be $-1.1 \times 10^{24} \mathrm{~m}^{-3}$ before condensation, with a pressure of $76 \mathrm{kPa}$ $(0.75 \mathrm{~atm})$. Since the peak Flibe vapor pressure $<1 \mathrm{~atm}$, the chamber would not explode. After a crack penetrated through the wall, air would rush in, quickly cooling the Flibe vapor to $\sim 850 \mathrm{~K}$ (slightly below the chamber wall temperature), and reducing its vapor pressure to about $0.1 \mathrm{~Pa}$ $(10.6 \mathrm{~atm})$.

Fine droplets could be generated from condensed vapor or from shattered spray droplets. Since they would tend to coalesce into larger drops, tiny droplets would have short lifetimes. As they cooled below $733 \mathrm{~K}$, the droplets would solidify into aerosol particles and gradually fall to the bottom or plate out on the chamber walls. The heated air leaving the crack by convection would carry with it some of the Flibe aerosol. If the upward convection velocity were $1 \mathrm{~m} / \mathrm{s}$, then only particles with radil $<64 \mu \mathrm{m}$ would be mobilized. After escaping the crack into the containment building, more of the aerosol particles would plate out. Lacking a definitive calculation of aerosol mass and size distribution, we estimate that about $1 \mathrm{~kg}$ of mobilizable aerosol particles might escape from the containment building. The aerosol size distribution and transport effects need further study.

Radioactivity release. The dominant activation product is about $300 \mathrm{MCi}$ of ${ }^{18} \mathrm{~F}$ in the Flibe. The $18 \mathrm{~F}$ offsite dose from the postulated accident would be $<0.2 \mathrm{mSv}(20 \mathrm{mrem})$. A pipe rupture, spilling many $\mathrm{m}^{3}$ of Flibe onto the building floor, would not produce a great ${ }^{18} \mathrm{~F}$ release, because the fluorine would remain chernically bound in the Flibe, with a very low vapor pressure $(\sim 10.4 \mathrm{~Pa}$ at $700 \mathrm{~K}$ ). The dose from activated pellet debris would be negligible.

The vuinerable tritium inventory released from Flibe in the chamber and from six fuel pellets would be $\sim 10 \mathrm{Ci}$ and $300 \mathrm{Cl}$, respectively. For a $3.5 \mathrm{~m}$ radius spherical blast chamber $10 \mathrm{~cm}$ thick with $30 \mathrm{~Pa}$ effective tritium overpressure, 
approximately $0.2 \mathrm{MCl}$ would be stored in the chamber wall. Cooling of the wall would retard outgassing of absorbed tritium. We use the estimates of offsite dose per $\mathrm{Cl}$ released of Piet, Cheng and Porter. 6 If all the $0.2 \mathrm{MCl}$ tritium plus the activation products in the mobilized Flibe were released, then the early offsite dose from these isotopes (under pessimistic aimospheric conditions) would be $\sim 3 \mathrm{mSv}(0.3 \mathrm{rem})$. This dose is far below the $2 \mathrm{SV}$ passive safety goal, and it is below the $50 \mathrm{mSv}$ ( $5 \mathrm{rem}$ ) level where evacuation plans need to be considered.

Nuclear Grade components. This estimated radioactivity release is also below the $0.25 \mathrm{SV}$ (25 rem) limit for nuclear grade components, ${ }^{7}$ so N-Stamp components would not be required in the HYLIFE-II reactor chambers or coolant loops. (If the entire inventory of radioisotopes were considered vulnerable, then some $\mathrm{N}$-stamp components would be required in the primary loop, but there are no sources of energy in the reactor sufficient to mobilize much Flibe or structure, so such a release is not credible.) If the maximum vulnerable tritium inventory in the target factory and tritium handling systems were less than $2.5 \mathrm{~kg}$, then the maximum offsite dose from its release would be less than $0.25 \mathrm{~Sv}(25 \mathrm{rem})$, and the N-Stamp requirement could be avoided for those systems, as well.

Chronic dose. For the severe accident case, the offsite chronic dose from 50 years exposure to groundshine plus inhalation of resuspended particles due to the postulated accident could be up to $0.23 \mathrm{mSv}$ (23 mrem), which would not be cause for concern.

Beryllium release. Escaping beryllium compounds such as $\mathrm{BeF}_{2}$ pose a health hazard. We must ensure that chronic leakage of Flibe does not constitute a threat to the health of plant workers, and that an accidental release of Flibe aerosol does not pose a health hazard to the public. The recommended limits are $25 \mu \mathrm{g} / \mathrm{m}^{3}$ for peak exposure to beryllium or its compounds and $2 \mu \mathrm{g} / \mathrm{m}^{3}$ for continuous exposure. ${ }^{8}$ If one $\mathrm{kg}$ of Flibe aerosol (containing $340 \mathrm{~g}$ of $\mathrm{BeF}_{2}$ ) were to escape both the blast chamber and the containment building over a period of one hour, the $\mathrm{Be}$ concentration at a $1 \mathrm{~km}$ site boundary under pessimistic atmospheric conditions would temporarily reach $3 \mu \mathrm{g} / \mathrm{m}^{3}$, which would be below the level of concern. However, the Be concentration within the plant could be high enough to require worker protection.

Safety Assurance Level. The HYLIFE-II reactor satisfies the criterion for "Safety Assurance Level $2^{n}$, moaning that large-scale passive protection can prevent serious consequences. ${ }^{9}$ In that respect, HYLIFE-II compares favorably with HYLIFE.I and with various magnetic confinement reactors. ${ }^{10}$

\section{MAINTENANCE}

The $\mathrm{NaBF}_{4}$ intermediate coolant loop will probably be accessible for some hands-on maintenance, because the external gamma dose rate will be low, but loss of tritium from the coolant must be prevented. Anticipated impurities in the Flibe could result in gamma dose rates too high for contact maintenance of the primary loop. For example, if $5.4 \mathrm{~kg}$ of $\mathrm{NaBF}_{4}$ intermediate coolant leaked into the primary loop, then the dominant activation products present one day after shutdown, following 30 years operation, would be $34 \mathrm{kCi}$ of $18 \mathrm{~F}, 2.1 \mathrm{kCi}$ of $22 \mathrm{Na}$, and $11.8 \mathrm{kCi}$ of ${ }^{24} \mathrm{Na}$. The resulting gamma dose rate outside a long steel pipe with radius $30 \mathrm{~cm}$ and thickness $1 \mathrm{~cm}$, containing this activity uniformly distributed in $750 \mathrm{~m}^{3}$ of Flibe, would be $0.85 \mathrm{~Sv} / \mathrm{hr}$ ( $85 \mathrm{rem} / \mathrm{hr}$ ). (This dose rate is from Ref. 1, adjusted for larger Flibe volume.) Similar impurities can result from other sources, such as those initially present in the Flibe, corrosion products, target debris, and $\mathrm{MoF}_{6}$ corrosion inhibitor (if used). Therefore, hands-on maintenance of the primary loop would probably not be feasible, unless the Flibe purification system were very efficient and the impurities did not plate out on pipe walls.

\section{WASTE DISPOSAL}

The dominant isotopes present in the manganese-stabilized stainless steel first wall after 30 years of irradiation will be $500 \mathrm{MCi}$ of $56 \mathrm{Mn}$ (half-life $2.6 \mathrm{~h}$ ) and $10 \mathrm{MCi}$ of $55 \mathrm{Fe}$ (half-life $2.7 \mathrm{y}$ ). ${ }^{5}$ After cooling 100 years, the total activity would decrease $1078 \mathrm{Cl}$ (mainly from ${ }^{99} \mathrm{Tc}$ and ${ }^{99} \mathrm{Nb}$ ), and the dose rate at the surface of the first wall would then be about $10 \mathrm{mSv} / \mathrm{h}$ (1 $\mathrm{rem} / \mathrm{h}$ ). This would be low enough for recycling by remote processing, but noi low enough 
for hands-on processing. The Shallow Land Burial index (ratio of activity to maximum allowable activity for thallow burial) would be 106, so Class $C$ disposal w - id not be an option. The Shallow Land Burial Index of the Flibe would be about 341 (due to ${ }^{14} \mathrm{C}$ ), but the Flibe could be recycled to other fusion reactors. Other massive components, such as the driver beam tubes, would have much lower indices.

\section{ACKNOWLEDGEMENT}

The authois are grateful to M. A. Hoffman, R. W. Moir, and D.K. Sze for helpful discussions. This work was supported by the US Department of Energy under contract DE-AC07-761D01570.

\section{REFERENCES}

1 T. J. Dolan and G. R. Longhurst, Safety and Environmental Issues of HYLIFE-II, EGG-FSP.8653, EG\&G Idaho (1989).

2 G. R. Longhurst and T. J. Dolan, "Tritium Permeation Losses Through HYLIFE-II Heat Exchanger Tubes", 9th Topical Meeting on the Technology of Fusion Energy, Oak Brook, IL (1990). (To be published in Fusion Technology).

${ }^{3}$ M. W. Rosenthal, P. N. Haubenreich, and R. R. Briggs, "The development status of Molten-Salt Breeder Reactors," ORNL-4812, Oak Ridge National Laboratory (1972).

4 G. R. Longhurst et al, "Atmospheric detritiation system performance," Fusion Technology 15, 1331 (1989).

5 R. W. Moir el al, "HYLIFE-\|l Progress Report," UCID-21816, Lawrence Livermore National Laboratory (1990).

6 S. J. Piet, E. T. Cheng and L. J. Porter, "Accident safety comparison of elements to define low activation materials," EGG.FSP.8552, EG\&G Idaho, 1989.

7 R. F. Bourque, I. Maya, K. R. Schultz, D. L. Sonn and R. K. Wise, "Fusion reactor cost reductions by employing non-nuclear grade components," Proceedings of the 12th Symposium on Fusion
Engineering, Monterey, CA, Oct.12-16, 1987, p.497-502, IEEE Catalog No. 87CH2507-2.

8 National Institute for Occupational Safety and Health, "Occupational Exposure to Beryllium," U.S. Government (1972). See also United States Federal Register, 36 105; quoted in Handbook of Chemistry and Physics, 56th Edition, R. J. Weast, Ed., CRC Press, Cleveland, Ohio (1975).

9 S. J. Plet, "Approaches to Achieving Intierently Safe Fusion Power Plants," Fusion Technology 10, 7 (1986).

$10 \mathrm{J.G}$. Delene and R. A. Krakowski, "Economic Implications for Fusion Derived from ESECOM Study," Nuclear Technology 15, 1225-1232 (1989).

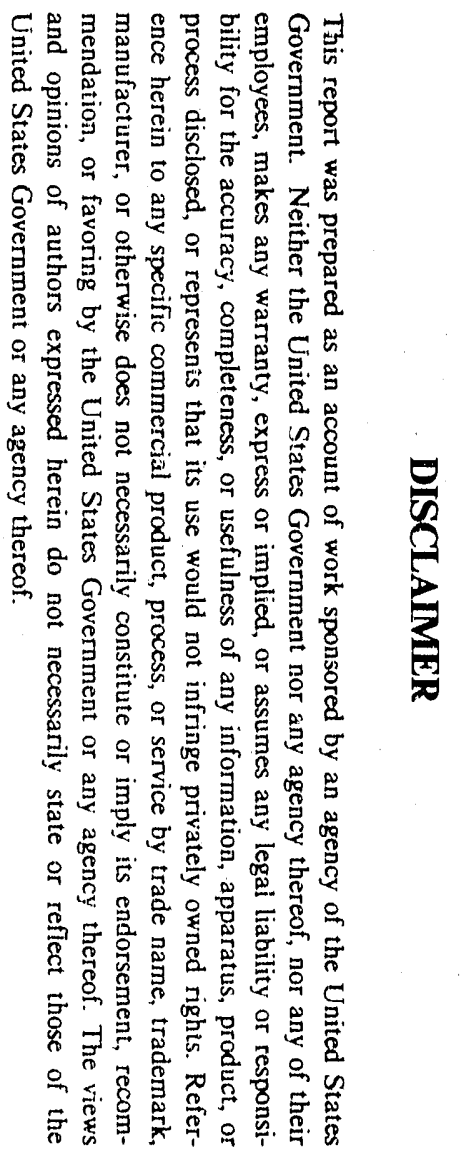



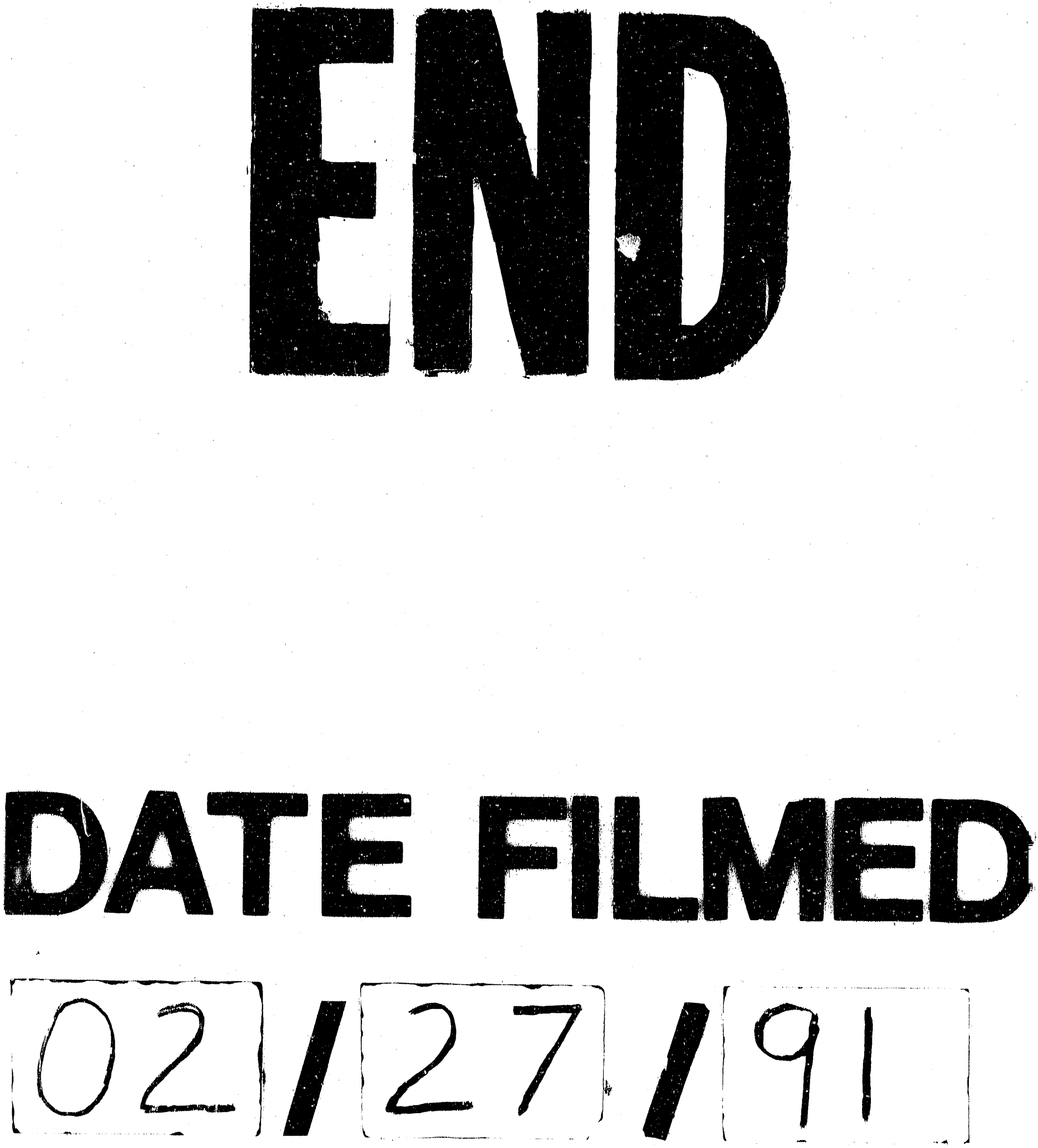


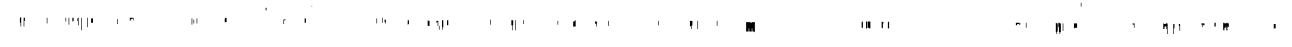

